\title{
Traffic Organization Optimization of Urban Road Combined Intersections
}

\author{
Haosen Zhang \\ College of Transport \& Communications, Shanghai Maritime University, Shanghai, China \\ Email: hszhang9527@163.com
}

How to cite this paper: Zhang, H.S. (2019) Traffic Organization Optimization of Urban Road Combined Intersections. Journal of Transportation Technologies, 9, 325-330. https://doi.org/10.4236/jtts.2019.93020

Received: May 13, 2019

Accepted: June 2, 2019

Published: June 5, 2019

Copyright $\odot 2019$ by author(s) and Scientific Research Publishing Inc. This work is licensed under the Creative Commons Attribution International License (CC BY 4.0).

http://creativecommons.org/licenses/by/4.0/

\begin{abstract}
With the development of the economy and the acceleration of urbanization, the number of vehicles in cities is increasing rapidly, which greatly increases the pressure on urban traffic. Solving traffic accidents and problems to keep smooth travel and safe travel has become a top priority in road construction. In this paper, how to optimize the traffic at the intersection of the urban road was discussed with the aim of reducing traffic accidents and problems to keep peoples' smooth travel and safe travel.
\end{abstract}

\section{Keywords}

Urban Road, Intersection Traffic, Traffic Organization, Optimization Design

\section{Introduction}

"The safety of people travel is greater than all", this has always been the basic thoughts advocated by the government, but according to incomplete statistics, every year, hundreds of thousands of traffic accidents occur in China, resulting in tens of thousands of deaths, hundreds of thousands of injuries, and direct property losses are calculated in billions of units, and these data are still increasing sharply every year. However, after investigation, it will be found that in fact, most of the accidents mainly occurred on highways or at intersections [1] [2] [3] [4]. Then, this paper focuses on how to optimize the traffic at the intersection of the urban road.

\section{Reasonable Optimization of Indicator Duration}

First of all, the traffic lights in the intersection are indispensable at each intersection, followed by the zebra crossing [5] [6] [7] [8] [9]. However, when the traffic light breaks down or the reading time of the traffic light is unreasonable, on the 
one hand, it is easy to cause traffic jams; on the other hand, many drivers are slightly manic now, which may cause friction or even accidents due to a sudden impulse. Therefore, these requirements require us to make reasonable design and changes for the red and green indicator lights. According to the different traffic flow of each period, the indicator light reading time should be reasonably arranged. For example, 7:00 am to 9:00 am is the peak period of work (the city may have a little bit difference in specific time), 5:00 am to 8:00 is the peak period for students to go to school. During this time, a significant proportion of traffic goes to the city or to the school district, so appropriate traffic light systems can be adjusted according to these routes and directions. From 5:00 to 8:00 in the evening is a peak time for going off work or going out of school, and the traffic light system can be adjusted according to the driving direction or road section with high traffic flow [8].

In the long run, the computer will also generate a statistical table of the peak period, According to the comprehensive statistics of the system; the indicator light can be reasonably regulated to facilitate the public and vehicles.

\section{Strengthen the Monitoring Layout of Intersections and Carry out the Real-Time Reports by Union Radio}

With the continuous increase of the number of vehicles between cities, the disadvantages of the road are becoming more and more obvious, especially the congestion problem. Every rush hour or the time of picking up students, the road can be blocked into "a parking lot". Now the city traffic is cross-linked, this requires us to carry out a comprehensive monitoring department for the intersection, and feedback to the monitoring center in real time, and cooperate with the city traffic radio and navigation APP to report on the road conditions in real time, by doing this, those who have not been stuck in the road to change the route in time, also can effectively avoid the delay of road information caused by the aggravation of traffic congestion. Of course, it is also necessary to give early warning to traffic congestion caused by emergencies in individual roads, such as friction between vehicles, traffic accidents or power failure of street lamps [2]. All these require to strengthen the monitoring layout of intersections, sensitivity and real-time of data transmission, which requires strict supervision and control.

\section{Improve Pedestrian and Non-Automatic Vehicles Crossing Facilities Based on City Conditions}

Due to the different economic developments between cities, the population density and vehicle density are different. In view of different situations, it is also necessary to carry out reasonable road planning, separate vehicles, trams, bicycles and pedestrians, and build overpasses or underground passageways at intersections. At the same time, it is also better to separate pedestrians and cyclists. Of course, this also needs to refer to the specific situation of urban development and traffic flow. For example, the road design of first-tier cities is definitely dif- 
ferent from that of third-tier and fourth-tier cities. For one thing, the economic budget is not enough; for another, the traffic volume of vehicles and pedestrians in cities is also different [3].

For example, Shanghai, a first-tier city in China, belongs to one of the cities with the highest economic development and population density in China. The traffic volume of both vehicles and pedestrians is very large, which requires very high urban roads. Viaducts and overpasses have become common road construction in Shanghai. In road construction, Shanghai has always been in the forefront of road construction in China. But it does not mean that there is no problem in the construction of Shanghai itself. The traffic flow and people flow in Shanghai are still improving; therefore, the requirements for Shanghai road are also improving. First, the separation of vehicles and pedestrians is based on traffic flow and traffic flow at the intersection. An overpass can be built, and the original pavement can be widened to make it a driveway. On the one hand, it can guarantee the safety of pedestrians, and on the other hand, it can ensure the smooth passage of vehicles [4].

Compared with those low-tier cities, the traffic flow is not so large, and the density of population is not so high, so the width of the road is not as high as that of Shanghai, However, it is imperative to conduct classified construction of roads between motor vehicles, non-motor vehicles and pedestrians, which can not only regulate traffic, but also greatly guarantee the safety of residents. Needless to say, building a flyover at the intersection can not only facilitate the travel of pedestrians, but also greatly guarantee the safety of vehicles (subject to the limitation of personal qualities, many citizens, Especially in low-tier cities, red light running is a serious problem, which poses a hidden danger to the safety of vehicles and pedestrians).

\section{Reasonable Channel Allocation for Intersection Lanes}

Nowadays, the traffic is in all directions, and it is in every direction. This requires channelized distribution according to different vehicles, such as go straight, left, right, and turn. These are the most basic road signs for roads. Reasonable channel allocation for roads can enable vehicles to drive orderly on roads and intersections, so as to avoid congestion. However, it can be found that there are only simple right turn and go straight + left turn, and there are only two lanes in many cities, which will lead to traffic congestion or even paralyse traffic during the period of sharp increase of traffic flow. All these require making reasonable channel subdivisions for lanes and roads, and appropriate statistics based on the number of vehicles traveling, and reasonable channel arrangements for the design of going straight and turning left combined with indicator lights [10].

At the high-speed intersection in Shanghai on December 18, three vehicles collided because of the unreasonable channelization of the roads. There was no reasonable division between going straight and turning left, and the situation of 
lane preemption occurred, resulting in a pile-up collision between three cars and the passenger car overturned. Fortunately, only minor injuries were caused, and no major casualties were caused.

\section{Rational Design of Intersections in View of the Road Engineering Construction}

When it comes to road engineering, it will inevitably touch on the quality of the project. The main purpose of road reconstruction is to improve the traffic environment. However, if the road quality is not controlled properly, it will not only cause a waste of funds, but also lead to huge hidden dangers to the smooth and safe travel of the people [9]. At the same time, it is also necessary to divide the intersection reasonably. First of all, the vision of the corner should be wide, and there should be no shielding objects higher than 1 meter, such as greening, Using small flowers and grass, to avoid planting shrubs and tall objects such as power poles set in the middle of the road. The corners are also designed to be round or curved as much as possible in a way that avoids instructing the design and avoid accidents caused by emergencies [7].

\section{Strengthen Road Monitoring and Improve Traffic Laws and Regulations}

"Nothing can be accomplished without norms or standards." Since ancient times, this is the rule. Therefore, it is necessary to strengthen the improvement of traffic laws and regulations, and to divide the responsibility for pedestrians, non-motor vehicles and motor vehicles. Subject to the shackles of the original idea "Motor vehicles bear most of the responsibility for accidents involving motor vehicles and pedestrians." This has caused pedestrians to be fearless. In fact, this is unreasonable. There is no binding force for pedestrian violations. Therefore, it is necessary to strengthen the monitoring layout of intersections, strictly monitor any dead angles, and improve the sensitivity of monitoring. Monitoring and shooting illegal behaviors such as running red lights at intersections and illegal driving of non-motor vehicles, take the responsibility to people, and formulating corresponding punishment measures [5].

For example, for pedestrians who run a red light in Shanghai, they are asked to watch all kinds of "death video" (Traffic accidents caused by running a red light and not obeying traffic rules), and then submit a post-view feeling; at the same time, there are also detailed rules such as fines for non-motor vehicles and pedestrians, as well as a clear division of responsibility for traffic accidents (if traffic accidents occur due to pedestrians, pedestrians take full responsibility) [11] [12] [13] and formally issue the "Several Provisions of the Shanghai Public Security Bureau on the Identification of Responsibility for Road Traffic Accidents", to carry out local legal provisions clearly, thereby increasing the restrictions on the uncivilized behavior of residents. These are all methods that are worth learning from everywhere [14]. 


\section{Conclusion}

In fact, in view of traffic organization optimization measures of urban road combined intersections, in addition to these, there are many places that can be advocated, such as encouraging residents to travel by bus and providing bus subsidies; advocating going green. Those who have a short distance can ride bicycles. For one thing, they can exercise their bodies, for another, they can reduce stress; the vehicle license plate rule is also a good solution [6], however, this method is not recommended unless there are special circumstances. All in all, it is necessary for the government to give full play to its supervision and management functions, formulate strict management measures, improve relevant laws and regulations and popularize them among residents. Only when the government manages well, publicizes well and the masses cooperate well can we fundamentally improve the urban traffic environment, reduce traffic pressure, reduce traffic safety hazards, and create a safe and convenient traffic environment for the masses [9].

\section{Conflicts of Interest}

The author declares no conflicts of interest regarding the publication of this paper.

\section{References}

[1] Liu, Y.D. (2016) Research on Traffic Organization Optimization of Urban Road Combined Intersections. Jiangxi Building Materials, No. 7, 11-12.

[2] Xie, Q.X. (2016) Analysis and Discussion on Traffic Organization Optimization of Urban Road Combined Intersections. Jiangxi Building Materials, No. 20, 87-88.

[3] Wang, C.X. (2015) Analysis on the Design of Urban Interchanges in the New Era. Academic Exchange Meeting on Architecture Technology and Management, March 2015, No. 2, 22-23.

[4] Peng, J. and Liu, Y.F. (2018) Discussion on the Current Traffic Organization Design of Urban Road Combined Intersections. Urban Construction Theory Research (Electronic Version), No. 11, 45-46.

[5] Li, G.C. (2018) A Brief Description on the Organization Optimization Design of Urban Road Combined Intersections. Heilongjiang Transportation Science and Technology, No. 7, 66-67.

[6] Wang, S.W. (2018) Discussion on the Key Points of Reconstruction Design of Urban Road Combined Intersections. Low Carbon World, No. 7, 66-67.

[7] Peng, J. and Liu, Y.F. (2018) Discussion on the Current Traffic Organization Design of Urban Road Combined Intersections. Urban Construction Theory Research (Electronic Version), No. 11, 34-35.

[8] Li, G.Q. (2016) Study on the Design Points of Urban Road Combined Intersections. Engineering and Technological Research, No. 5, 123-125.

[9] Wu, C. (2015) Research on Optimization Design of Urban Road Combined Intersections. Sichuan Cement, No. 3, 75-76.

[10] Zhang, Z.S. (2018) Reform and Optimal Design on Ground Intersection under Elevated Road. Transportation and Transportation (Academic Edition), No. 1, 
112-114.

[11] Chen, C., Shao, Y.B. and Yang, J. (2013) Experimental and Numerical Study on Fire Resistance of Circular Tubular T-Joints. Journal of Constructional Steel Research, 85, 24-39. https://doi.org/10.1016/j.jcsr.2013.02.013

[12] Smith, S.L., Tumova, J., Belta, C. and Rus, D. (2011) Optimal Path Planning for Surveillance with Temporal-Logic Constraints. The International Journal of Robotics Research, 30, 1695-1708. https://doi.org/10.1177/0278364911417911

[13] Kim, K.D. (2013) Collision Free Autonomous Ground Traffic: A Model Predictive Control Approach. ACM/IEEE International Conference on Cyber-Physical Systems, Philadelphia, Pennsylvania, 8-11 April 2013, 51-60.

https://doi.org/10.1145/2502524.2502532

[14] Yoon, Y., Shin, J., Kim, H.J., Park, Y. and Sastry, S. (2009) Model-Predictive Active Steering and Obstacle Avoidance for Autonomous Ground Vehicles. Control Engineering Practice, 17, 741-750. https://doi.org/10.1016/j.conengprac.2008.12.001 